\title{
Journal of Cardiovascular Medicine and Cardiology EPeertechz
}

\begin{abstract}
Suna Aydin*
Department of Cardiovascular Surgery, Elazig

Research and Education Hospital, Elazig 23100 Turkey

Dates: Received: 01 November, 2016; Accepted: 15 November, 2016; Published: 16 November, 2016

*Corresponding author: Suna Aydin, MD, PhD, Department of Cardiovascular Surgery, Elazig Research and Education Hospital, Elazig 23100, Turkey, Tel: (90) 532-785-6138: E-mail: cerrah52@hotmail.com www.peertechz.com

ISSN: 2455-2976
\end{abstract}

\section{Editorial}

Cardiac cachexia, a syndrome characterized by systemic destruction, nutritional impairment and weight loss [1], has a prevalence ranging between 8 and $42 \%$ around the world [2]. The syndrome was first described by the father of medicine, Hippocrates, as follows: "the flesh is consumed and becomes water; shoulders, clavicles, chest and thighs melt away. The illness is fatal" [3]. Currently the most widely accepted description of primary cachexia is, in the presence of congestive heart failure, nonvoluntary loss of $>6 \%$ of non-edematous body weight in less than 6 months $[1,3,4]$. Although the pathophysiological changes causing cardiac cachexia have not been fully clarified since the time of Hippocrates, it is suggested that nutritional impairment, gastrointestinal disorders, anabolic and catabolic imbalance, and neurohormonal and immune anomalies play a significant role in its development [1]. In addition to these major mechanisms, this perspective will focus on the possible role of irisin in the development of cardiac cachexia and heart attack

Hormone Irisin, a proteolytic product of the type III domain 5 of fibronectin, a transmembrane protein, was first shown by Bostrom et al. to be elevated in the skeletal muscle and released to the circulation after exercise [5]. Following its discovery in the skeletal muscle, irisin was reported to be produced by a number of biological tissues, including the heart tissue [6]. The main function of this protein is to mediate the conversion of white fat tissue into brown fat tissue and to increase the amounts of uncoupling proteins in brown fat tissue mitochondria, thereby causing heat production, rather than ATP synthesis. ${ }^{5}$ With such physiological effects (increasing energy consumption), irisin has become a promising agent in the treatment of metabolic diseases such as the metabolic syndrome, obesity, and type 2 diabetes mellitus [6].

Patients diagnosed with cardiac cachexia have elevated levels of irisin (manuscript in preparation). Consequently, elevated irisin in both circulation and tissues may, by increasing the amount of uncoupling proteins, preventing the formation of ATP through mitochondrial oxidative phosphorylation, and causing heat energy release instead of ATP [5,6], lead to continuous energy loss and contribute to the development of cardiac cachexia [3,4]. In other words, the higher the irisin levels in circulation are, the more fat is lost and the more reduction is seen in muscles and other tissue masses. Consequently, patients predisposed to cardiac cachexia may be administered anti-irisin preparations to inhibit this condition.

Similarly, it is known that the heart muscle can use glucose, plasma free fatty acids, lactate, pyruvate, ketone bodies, triglycerides, and amino acids, to a very small extent, as sources of energy $[7,8]$. However, the urgent energy need of the myocardial tissue is met through the hydrolysis of adenosine triphosphate (ATP) [9]. Increased irisin in circulation mediates uncoupling proteins to cause high energy release instead of ATP synthesis $[5,6]$. Mitochondria form the $35-40 \%$ of the total volume of the heart muscle [10]. Almost entire ATP produced under normal circumstances is provided by mitochondrial oxidative phosphorylation $[9,10]$. Therefore, irisin concentrations elevated by exercise [5] may lead to a decrease in the production of adenosine triphosphate (ATP) which meets the urgent energy needs of the myocardial tissue, and cause the death of myocardial tissue, or in other words, a myocardial infarct. There may be a correlation between mortality associated with myocardial infarct occurring after heavy exercise and circulating amounts of irisin (more generally speaking, the amounts of uncoupling proteins).

Consequently, a fat-burning molecule, irisin, may not only mediate cachexia (including cardiac cachexia), but also be among the major causes of heart attacks due to its restriction of the production of adenosine triphosphate which satisfies the pressing energy needs of the myocardial tissue. It is believed that consideration given to the mechanisms suggested here might lay the groundwork for many studies aiming to prevent cachexia and heart attack, which are among the principal public health problems in all societies, and help avoid these two common health problems.

\section{References}

1. Evans WJ, Morley JE, Argile's J, Bales C, Baracos V, et al. (2008) Cachexia: a new definition. Clin Nutr 27: 793-799.

2. Christensen HM, Kistorp C, Schou M, Keller N, Zerahn B, et al. (2013) Prevalence of cachexia in chronic heart failure and characteristics of body composition and metabolic status. Endocrine 43: 626-634.

3. Pittman JG, Cohen P (1964) The Pathogenesis of Cardiac Cachexia. N Engl J Med 271: 453-460.

4. Cohen S, Nathan JA, Goldberg AL (2015) Muscle wasting in disease: molecular mechanisms and promising therapies. Nat Rev Drug Discov 14: 58-74.

5. Boström P, Wu J, Jedrychowski MP, Korde A, Ye L, et al. (2012) A PGC1-? dependent myokine that drives brown-fat-like development of white fat and thermogenesis. Nature 11: 463-468. 
6. Aydin S (2014) Three new players in energy regulation: preptin, adropin and irisin. Peptides 56: 94-110.

7. Depre C, Vanoverschelde JL, Taegtmeyer H (1999) Glucose for the heart Circulation 99: 578-588.

8. Aubert G, Martin OJ, Horton JL, Lai L, Vega RB, et al. (2016) The Failing Heart Relies on Ketone Bodies as a Fuel. Circulation 133: 698-705.
9. Ingwall JS, Weiss RG (2004) Is the failing heart energy starved? On using chemical energy to support cardiac function. Circ Res 95: 135-145.

10. Page E, McCallister LP (1973) Quantitative electron microscopic description of heart muscle cells. Application to normal, hypertrophied and thyroxinstimulated hearts. Am J Cardiol 31: 172-181 